
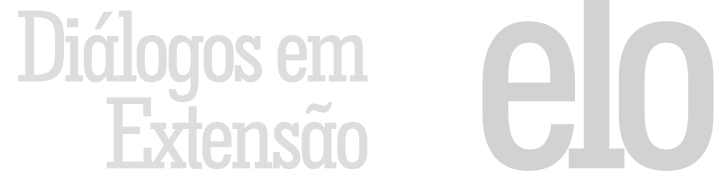

\title{
O uso do jornal impresso como estratégia para a formação do leitor crítico
}

\author{
Luciana de Carvalho Medeiros ${ }^{1}$
}

\begin{abstract}
RESUMO: Este trabalho apresenta os resultados de uma experiência de ensino realizada numa turma de Ensino Médio de uma escola periférica da cidade de Viçosa-MG. Tornou-se relevante repensar novas estratégias para instigar os estudantes a ler mais e a buscar mais informações, uma vez que notava- se pouca informatividade nas redações dos discentes e pouca desenvoltura dos mesmos em captar informações, até mesmo explícitas na superfície textual ou expostas por meio de paráfrases. $O$ jornal foi escolhido como instrumento didático por este ser um suporte que abarca diversos gêneros textuais, além de apresentar informações sobre questões contemporâneas. A partir de leituras, debates e análise crítica das informações jornalísticas, foi possivel trabalhar as ideologias dos discursos midiáticos. Destarte, este trabalho convida a comunidade docente, bem como a sociedade em geral, a refletir sobre a inserção de instrumentos de comunicação no espaço escolar como acréscimo à limitação dos textos do livro didático, intervindo na rotina da sala de aula.
\end{abstract}

Palavras chave: Ideologias, jornal impresso, leitor crítico.

Áreas temáticas: Educação e comunicação.

${ }^{1}$ Graduação em Letras UFV - Bolsista PIBID/CAPES. 


\section{Using printed newspaper as a strategy for training critical reader}

ABSTRACT: This paper presents the results of a teaching experiment carried out in a peripheral high school class in Viçosa-MG. It is important to get new strategies to urge students to read more and seek more information, since we noted little inquiries after composition classes and little progress by them on getting information, even on explicit texts or exposed through paraphrasing. Newspaper was chosen as a teaching tool because it is a support that embraces several textual genders and presents information on contemporary issues. From readings, debates and critical analysis of journalistic information it was possible to discuss ideologies of media discourse. Thus, this work invites the teaching community as well as society in general to ponder over the insertion of communication tools in school as an addition to the limitation of texts from textbooks intervening in the classroom routine.

Keywords: Critical reader, ideologies, newspaper printed.

Thematic area: Education and communication.

\section{Usar el periodic impreso para la formacion del lector cri- tico}

RESUMEN: Este trabajo presenta los resultados de un experimento llevado a cabo la enseñanza en una clase de la escuela secundaria a las escuelas periféricas de Viçosa-MG. Se convirtió en importante repensar nuevas estrategias para atraer a los estudiantes a leer más y buscar más información, ya que hemos observado poco informativo de los estudiantes en las salas de redacción y poco ingenio de los estudiantes en la captura de información, incluso en la superficie textual explícita o expuesta a través de paráfrasis. El periódico fue elegida como una herramienta de enseñanza, ya que es un soporte que se extiende por varios géneros y presenta información sobre temas de actualidad. A partir de lecturas, debates y análisis crítico de la información periodística, fue posible trabajar ideologías del discurso mediático. Esta obra invita a la comunidad educativa ya la sociedad en general, para reflexionar sobre la integración de las herramientas de comunicación en la escuela como una adición a la limitación de los textos del libro de texto, que interviene en la rutina de la clase.

Palabras clave: Ideologías, lector crítico, periódico impreso.

Área temática: Educación y comunicación. 


\section{APRESENTAÇÃO}

O escoamento da informação impressa e digital na sociedade atual se dá de forma cada vez mais veloz, mas isso não garante que toda a população leia, ou seja, não basta que haja meios de informação para que aconteça a leitura; é preciso saber ler, gostar de ler e praticar a leitura cotidianamente. Muitos estudantes leem apenas quando são obrigados, para conseguir pontuação necessária na escola. O processo de leitura, nesse caso, torna-se superficial, mecânico, puramente para atender critérios de avaliação e, consequentemente, muitos alunos encontram dificuldades para redigir textos porque possuem um repertório mínimo de informações. Com os objetivos de tornar as aulas de Português mais atrativas e contextualizadas, incentivar a autonomia do aluno para o hábito da leitura, aprimorar as competências textuais dos estudantes e contribuir para a formação de um leitor crítico, autônomo e cidadão, este relato de experiência apresenta os resultados obtidos na utilização do jornal impresso como instrumento pedagógico. Tornou-se relevante repensar novas estratégias para instigar os alunos do ensino médio da Escola Estadual Raul de Leoni, envolvidos no PIBID - Programa Institucional de Bolsa de Iniciação à Docência de Língua Portuguesa, a ler mais e a buscar mais informações, uma vez que notou- se a pouca informatividade nas redações dos discentes e pouca desenvoltura dos mesmos em captar informações até mesmo explícitas na superfície textual ou expostas por meio de paráfrases. $\mathrm{O}$ jornal foi escolhido como instrumento didático por este ser um suporte que abarca diversos gêneros textuais, além de apresentar informações sobre questões contemporâneas. A partir das leituras, debates e análise crítica das informações jornalísticas foi possível trabalhar as ideologias dos discursos midiáticos e diversos assuntos atuais na sociedade. Como resultado, observou-se que os alunos passaram a produzir textos com maior rigor argumentativo e mais elaborados, além de conseguirem perceber a importância social da leitura e da informação. No contexto escolar, o jornal pode ser utilizado para promover a socialização visando uma educação baseada na cultura e no conhecimento, uma vez que é um veículo informativo de caráter dinâmico, disseminador de informações inseridas em contextos da atualidade. Destarte, este trabalho convida a comunidade docente, bem como a sociedade em geral, a refletir sobre a inserção de instrumentos de comunicação no espaço escolar como acréscimo à limitação dos textos do livro didático, intervindo na rotina da sala de aula.

\section{CARACTERIZAÇÃO DO AMBIENTE ESCOLAR}

A Escola Estadual Raul de Leoni é um estabelecimento oficial de ensino, atendendo aos regimes de Ciclo e seriação, no Ensino 
Fundamental e Médio. A instituição recebeu esse nome em homenagem ao poeta parnasiano Raul de Leoni, nascido no estado do Rio de Janeiro em 1895. O colégio foi fundado pelo Padre Antônio Mendes, professor e capelão da UFV, começando a funcionar em 1992. Situada na Rua Mário Dutra dos Santos s/n, no bairro Santo Antônio em Viçosa-MG, com uma área de $6.240 \mathrm{~m}^{2}$, a instituição de ensino possui um amplo espaço físico, arborizado. A instalação conta com 12 salas de aula, 1 laboratório de Informática equipado com computadores de qualidade, 1 laboratório de Ciências, 1 biblioteca bem equipada, 1 sala para professores, 1 para a supervisão, 1 para a diretoria e 1 secretaria ampla. A escola oferece ao estudante uma boa infraestrutura, disponibilizando aos docentes recursos audiovisuais e bons materiais didáticos para suporte.

A instituição oferece as modalidades de ensino fundamental e médio, atendendo uma demanda total de 466 alunos. O colégio, atualmente, conta com o apoio de projetos multidisciplinares, como o PIBID/Língua Portuguesa e Matemática. Outros projetos autônomos são realizados na escola, demonstrando que a instituição reconhece a importância do diálogo com a universidade.

O estabelecimento oficial de ensino Raul de Leoni organiza-se como uma instituição apolítica, com o objetivo de proporcionar ao educando a formação necessária ao desenvolvimento de suas potencialidades, para sua auto - realização, preparando-o para o exercício consciente da cidadania e prosseguimento nos estudos, conforme as determinações da Lei nº 9.394/96 de 23 de dezembro de 1996.

O segmento de ensino adotou como auxílio à proposta pedagógica o projeto escola Tempo Integral voltado para todos os alunos que desejam o sucesso escolar e não somente aqueles com dificuldades ou com problemas de aprendizagem. Sob a proposta de oferecer à comunidade estudantil um ensino de qualidade, os objetivos do colégio são: dar formação aos alunos para que esses prossigam seus estudos, prepará-los para a cidadania, aprimorar o educando como pessoa humana, incluindo a formação ética e o desenvolvimento da autonomia intelectual e do pensamento crítico, atender às necessidades formativas dos alunos, conforme texto do Projeto Político Pedagógico da Escola.

A escola Estadual Raul de Leoni recebe alunos das localidades próximas de Viçosa, moradores das periferias locais e da zona rural. No Ensino Médio, estão matriculados alunos que têm entre 16 e 21 anos de idade.

A organização pedagógica da instituição é ostensiva, priorizando sempre o bom desempenho no processo de ensino e aprendizagem do aluno. Nesse sentido, a escola compromete-se a oferecer uma 
educação de qualidade, que respeite a realidade social e individual do educando no processo de construção de sua cidadania, baseando-se nos princípios norteadores da LDB - Lei de Diretrizes e Bases da Educação Nacional.

Quanto ao conteúdo de Língua Portuguesa, a escola prepara o estudante para ser capaz de confrontar pontos de vista e opiniões diversas, aplicando e adaptando a língua aos vários contextos sociais, além de gabaritá-lo a construir um imaginário através da interpretação, leitura e produção textual, realizando, por meio destes, acordos e condutas sociais.

O Índice de Desenvolvimento da Educação Básica - IDEB que busca representar a qualidade da educação a partir da observação dos aspectos fluxo (progressão ao longo dos anos) e o desenvolvimento dos alunos (aprendizado) da escola, em 2011, foi de 3,8. Para aprimorar o ensino no local, o PIBID de Português objetiva ampliar, dinamizar e promover atividades de leitura e produção de textos para alunos do Ensino Médio visando a formação de leitores críticos dos textos e das realidades sociais.

\section{FUNDAMENTAÇÃO TEÓRICA}

Os conteúdos tradicionais de uma aula de língua portuguesa (o ensino de gramática, produção textual e literatura), segundo a nova reformulação dos Parâmetros Curriculares Nacionais, foram incorporados à perspectiva da linguagem, entendida essa como um campo maior, dialógico, no qual acontece a comunicação entre os locutores.

À luz dessa perspectiva, o trabalho com o texto proporciona possibilidades variadas de uso da linguagem, pautando-se pelo contexto. Os livros didáticos adotaram a perspectiva do documento PCN para o ensino de língua portuguesa, estando a cargo do profissional de ensino aplicar as atividades da grade de modo a abarcar todos os conhecimentos propostos no currículo de Língua Portuguesa.

O ensino da língua materna, de acordo com os PCN's, deve ter como unidade o texto, o qual se constrói "dentro de um determinado gênero em função das intenções comunicativas, como parte das condições de produção dos discursos, as quais geram usos sociais que os determinam" (SEF, 1998, p.21).

O ensino de Língua Portuguesa tem sido alvo de questionamentos. Ao longo dos anos, tem-se percebido que uma parcela considerável de alunos do sistema público não apresenta domínio, nem para confeccionar textos, nem para entender informações que exigem do interlocutor um nível médio de informatividade. 
Para tentar superar as barreiras expostas acima, tornou-se necessário introduzir o jornal em sala de aula, como alternativa para estimular a leitura e a interpretação de textos e por este instrumento apresentar riqueza de textos, possibilitando um trabalho interativo e contextualizado, a partir de gêneros textuais e de ideologias discursivas.

A mídia impressa utilizada como instrumento didático, os jornais, selecionados previamente pelo professor, podem ser fontes interessantes para pesquisa e de obtenção de informação sobre o mundo contemporâneo. Com o passar dos tempos, eles se tornaram mais modernos, passando por reestruturações gráficas e editoriais, para atender as expectativas dos mais diversos leitores.

Conforme a pesquisadora e autora de diversos livros sobre o tema inserção do jornal em sala de aula, Maria Alice Faria (2003) apresenta este instrumento como mediador entre a escola e o mundo, sendo o jornal "uma fonte primária de valores, tornando-se então, instrumento importante para o leitor se situar e se inserir na vida social e profissional" (FARIA, 2003, p.11). Para Faria (2003), o aluno será capaz de criar um filtro seletivo sobre suas leituras, quando souber lidar com o excesso de informação e, a partir daí, terá desenvoltura suficiente para selecionar os fatos, organizá-los, analisá-los e criticá-los.

Ainda consoante Faria (1996),

a linguagem jornalística oferece hoje uma espécie de português fundamental, uma língua de base, não tão restrita que limite o crescimento linguístico do aluno e nem tão ampla que torne difícil ou inacessível o texto escrito ao comum dos estudantes (FARIA, 1996, p.12).

Várias são as vantagens da utilização da mídia impressa na sala de aula, porém, o professor deve se atentar para que o jornal não seja utilizado de forma superficial, apenas para se trabalhar conteúdos gramaticais ou a realização de leituras superficiais, que excluem o texto do contexto.

No jornal há diversos tipos e gêneros textuais. Dessa forma, o trabalho com os textos jornalísticos em sala de aula é uma estratégia interessante de ensino, principalmente se o texto for reconhecido como lugar de articulação de discursos e interação dialógica dos sujeitos.

Partindo da necessidade de fazer com que os alunos se vejam como sujeitos responsáveis pela construção de sentidos, compreende-se, conforme as palavras de Orlandi (2005) que: 
Não é só quem escreve que significa: quem lê também produz sentidos. E o faz, não como algo que se dá abstratamente, mas em condições determinadas, cuja especificidade está em ser sócio- históricas (ORLANDI, 2005, p.58).

Sob a perspectiva da Análise do Discurso e da Semiótica, Cheida (2006) afirma que:

O jornal serve como intermediador dotado de características ideológicas e valorativas que precisam ser conhecidas para a referência de leitura crítica sobre o modo de fazer o jornal e como esse modo lê a realidade e qual a realidade (CHEIDA, 2006, p.07).

Observadas as necessidades dos discentes, pretendeu-se, com este trabalho, levar ao aluno do Ensino Médio, atividades contextualizadas, instigando a percepção do texto jornalístico como meio de produção de ideologias e significados, a fim de tornar os estudantes leitores críticos e potenciais.

\section{DESCRIÇÃO DA EXPERIÊNCIA}

Para subsidiar o trabalho com a mídia impressa em sala de aula, os gêneros discursivos não foram isolados do suporte ao qual eles se inserem. Ou seja, para não tornar os gêneros jornalísticos meros gêneros escolarizados, o jornal foi levado para a sala de aula sem recortes, para que os alunos tivessem contato com situações comunicativas contemporâneas e reais. Portanto, era preciso que os discentes encarassem a leitura como atividade sociointeracional, pois não se pretende formar leitores passivos, ou seja, que veem o processo de leitura apenas como o ato de decodificar palavras.

Primeiramente foi observada a necessidade de exploração da leitura em sala de aula, haja vista a produção de textos carentes de informatividade por parte dos estudantes.

No Ensino Médio, espera-se que os alunos já tenham certo domínio da produção textual e que sejam leitores críticos, mas isso nem sempre acontece. O que se observa por parte de muitos estudantes é a carência de leitura, pois não é difícil para um professor encontrar textos com pouco rigor argumentativo.

Em seguida, os alunos foram questionados se fazem a leitura de textos jornalísticos e o que este suporte representa para os estudantes. Foi observado que os alunos não tinham muito contato com 
a leitura de textos de jornais, a não ser daqueles que geralmente aparecem recortados nos livros didáticos.

Com essa investigação, pode-se notar a necessidade de inserção da mídia na sala de aula e, com isso, realizar trabalhos intensivos que visassem à formação de leitores críticos dos jornais impressos.

Foi solicitado aos alunos que pesquisassem o histórico de quatro jornais impressos, sendo eles Folha de São Paulo, O Globo, jornal Zero Hora e jornal O Tempo. Posteriormente, as mídias impressas foram levadas para a sala de aula para que os alunos (divididos em grupos) pudessem folheá-las e observar como cada suporte se organiza. Nessa etapa, foi possível realizar diversas experiências de leitura.

Vale ressaltar que os jornais levados para a sala de aula foram selecionados pelo professor e pelo bolsista PIBID que aplicaram as atividades com as mídias impressas. Os jornais utilizados foram escolhidos por serem conhecidos regionalmente e nacionalmente e por apresentarem certo prestígio social.

É importante salientar também que todas as atividades foram realizadas em grupos, para tornar a atividade mais interativa e possibilitar o diálogo entre os alunos.

Foram realizados trabalhos com os gêneros jornalísticos em que os alunos deveriam observar e categorizar as características de cada gênero, bem como observar a funcionalidade destes e o público alvo a quem estes se destinam. Neste processo, os discentes produziram dissertações e debates sobre algumas notícias dos jornais, analisaram as formas de informação e fizeram um levantamento dos elementos dos jornais (reportagem, anúncios publicitários, charges etc.). Nestas atividades, os estudantes puderam observar que cada gênero tem características próprias e se vale de recursos específicos, como a utilização ou não da linguagem verbal e não- verbal.

Os alunos puderam ver que há textos que permitem o uso de gírias e outros não, e entender porque isso ocorre, analisando a adequação ao contexto comunicativo.

Numa fase posterior, vários textos jornalísticos que tratavam de um mesmo assunto político foram levados para a sala de aula e esta, posteriormente, foi dividida em grupos. Cada equipe ficou responsável por elencar palavras e características marcantes de um líder político (Barack Obama), bem como analisar as imagens ligadas aos gêneros jornalísticos em questão. A tarefa dos alunos seria observar como cada texto jornalístico inserido numa mídia impressa específica constrói a imagem de um sujeito, ou quais recursos são utilizados para despertar a atenção do leitor para determinado assunto. 
Os grupos elencaram as características dos gêneros jornalísticos, a imagem do representante político e, com isso, relacionaram a forma como cada jornal trata o político com as ideologias dos jornais pesquisados. Portanto, a tarefa dos alunos foi comparar o tratamento dado a um mesmo fato em diferentes jornais.

\section{RESULTADOS}

A sala de aula foi dividida em quatro grupos. Cada grupo ficou responsável por redigir um texto e apresentar para a turma, comparando o tratamento dado à imagem de Barack Obama após o resultado das eleições norte-americanas. Os grupos já conheciam, por pesquisas realizadas anteriormente, cada uma das mídias impressas que seriam utilizadas para análise.

Antes que a sala recebesse os jornais, foi discutido com os estudantes um breve histórico sobre a figura pública Barack Obama. Posteriormente, os estudantes receberam os jornais e iniciaram as atividades.

O primeiro grupo, que recebeu o jornal Folha de São Paulo, afirmou o seguinte:

O presidente reeleito Barack Obama está sendo representado no jornal Folha de São Paulo na matéria "Reeleito, Obama enfrenta desafios na economia e na política externa" como uma figura trabalhadora, que quer/deverá agir na política do país de modo intenso. A matéria diz que Obama conseguiu vitória clara, mas precisará lidar com dificuldades da economia americana. A imagem do político aparece em uma foto segurada por um cidadão que claramente apoiou a reeleição de Obama, demonstrando estar feliz com a vitória do candidato. Atrás do cidadão está um grupo de pessoas e para nós, parece que este grupo também apoiou a recandidatura. (Grupo 1)

Já a segunda equipe, que analisou o discurso do jornal O Globo, fez as seguintes ponderações:

Na notícia "Obama é reeleito com país e Congresso divididos", a recandidatura do político foi entendida como uma forma de se fazer permanecer a divisão do Congresso, com os democratas sob o controle do Senado e os republicanos com o domínio na Câmara. A reeleição, conforme o jornal mostra, deve ser comemorada, porém Obama começa o seu segundo mandato num momento delicado da economia do país, que enfrenta um déficit anual de 1 trilhão de dólares e o 
impasse dos partidos republicano e democrata. Para nós do grupo, a matéria parece expor o que o presidente reeleito deverá enfrentar nos próximos quatro anos de mandato e mostra que a disputa presidencial foi acirrada. (Grupo 2)

O terceiro grupo, valendo-se da análise da imagem de Barack Obama, associada à manchete "Ele é o cara" fez as seguintes considerações:

No jornal Zero Hora, o presidente Barack Obama aparece sendo uma figura exaltada, um mito da política externa, como uma verdadeira figura idealizada, um modelo de político a ser seguido. Na imagem, o político aparece sorridente apoiado em um comentário que ele mesmo fez, agradecendo os eleitores no Twitter. $\mathrm{O}$ jornal exalta o caráter de líder popular do político e mostra que ele frequenta as redes sociais, dando atenção aos eleitores até nestes meios de comunicação. Um verdadeiro líder carismático. O próprio título demonstra grandiosidade do candidato reeleito. (Grupo 3)

O quarto grupo fez as seguintes considerações a respeito da reeleição do presidente dos Estados Unidos:

Na matéria do dia 08/11, do jornal O Tempo, com o título "Reeleito: o melhor está por vir", Barack Obama é representado como uma pessoa que levará esperança ao povo dos Estados Unidos. Na matéria, o lado familiar dele foi explorado e o político ressaltou a importância da democracia no seu mandato. A imagem de Obama foi construída como se ela pudesse passar esperança para os leitores. Nós, do grupo, sentimos que o jornal quis ressaltar a imagem de determinação do presidente frente aos antigos e novos desafios. (Grupo 4)

Observa-se nos textos supradiscriminados, pontos de vista diferentes a respeito da figura de Barack Obama. Os alunos perceberam que cada jornal utiliza uma palavra específica para denotar o político (político, cidadão, líder carismático etc.) e assim, uma imagem específica vai se criando na mente de cada leitor, à medida que este se deixa convencer por certo discurso. Afinal, a mídia constrói personagens ou é fiel à realidade? Os alunos puderam notar que cada jornal aporta uma ideologia acerca daquilo que divulga e, cabe ao leitor, criticar aquilo que lê.

Com este trabalho, foi possível promover discussões sobre o papel da imprensa, bem como capacitar o estudante a ler criticamen- 
te, promovendo o respeito aos pontos de vista distintos por meio de debates ideológicos. Foi possível, também, aproximar a sala de aula das questões cotidianas e fazer com que os alunos visualizassem as aulas de Língua Portuguesa como de uma disciplina essencial para a formação escolar e cidadã.

Os alunos conseguiram captar a influência ideológica na escolha das imagens e das palavras para a composição de uma notícia ou de outros gêneros contidos no jornal.

O mais importante foi notar que os estudantes passaram, depois destas atividades com jornal, a fazer leituras reflexivas e a produzir textos com maior rigor argumentativo, utilizando com maior fluência os meios linguísticos. Atividades como esta devem ser realizadas para estimular os alunos a observar mais profundamente o texto que estão lendo, seja através das informações explícitas, seja através das informações externas ao texto, mas que ajudam na construção do sentido.

O trabalho de análise da notícia jornalística, tal como foi feito, foi relevante por mostrar aos alunos que pode- se/deve- se respeitar pontos de vista distintos, mesmo discordando daquilo que é dito. Comparando as notícias, os estudantes notaram que os jornais apresentam visões de mundo diversas a todo o momento, ora (re) criando estereótipos, ora apresentando a realidade semelhante aos fatos ocorridos. Neste sentido, é papel do papel do leitor consciente, crítico e autônomo refletir sobre o mundo que os jornais nos apresentam e, assim, produzir significados.

\section{CONSIDERAÇÕES FINAIS}

As atividades propostas serviram como meio de avaliar se o trabalho com jornais em sala de aula surtiria efeitos positivos e se os alunos estariam se tornando leitores mais críticos. Com as atividades realizadas, os alunos melhoraram na produção escrita, na medida em que começaram a ter mais contato com a leitura. Nota-se, portanto, que o aluno precisa adquirir uma visão de cidadão na sociedade, mas antes disso precisa ter senso crítico.

É importante que o texto seja explorado na sala de aula nos mais diversos tipos e gêneros, para que se amplie o leque de conhecimento dos alunos e os tornem competentes para as configurações do universo textual, fazendo com que visualizem a importância do texto, tanto oral quanto escrito, para as relações comunicativas, dentro e fora da escola.

Formar alunos competentes para a leitura, interpretação e compreensão de textos é um desafio para muitas escolas, mas todas elas 
devem entender que nenhum aluno saberá compreender, escrever ou discorrer sobre algo se não tiver domínio sobre um assunto, ou mesmo não tiver o hábito de praticar a leitura e buscar informação.

É essencial que a instituição escolar crie mais atividades de leitura que dialoguem com as atualidades, pois é eminente que os estudantes conheçam o mundo que os cerca. A disciplina Língua Portuguesa, acima de tudo, deve fomentar o exercício da cidadania e colaborar para a construção de um conhecimento mais amplo, atualizado e multidisciplinar do estudante. O aluno só exercerá a função social da escrita se souber de fato ler, interpretar e produzir textos e não meramente decodificar textos. A utilização de mídias impressas na sala de aula pode ser uma alternativa interessante para a condução do ensino da disciplina Língua Portuguesa.

\section{REFERÊNCIAS BIBLIOGRÁFICAS}

CHEIDA, M.J. O jornal na tensa fronteira entre o público e o privado: um estudo para ler criticamente os jornais em sala de aula. Anais do $3^{\circ}$ Seminário nacional O Professor e a Leitura do Jornal - 2006. Disponível em: http://www.alb.com. br. Acesso jul. 2012.

FARIA, M.A. Como usar o jornal na sala de aula. São Paulo: Contexto, 2003. . O jornal na sala de aula. 7.ed. São Paulo: Contexto, 1996.

ORLANDI, E.P. O inteligível, o interpretável e o compreensível. In: ZILBERMAN, R.; SILVA, E.T. Leitura: perspectivas interdisciplinares. 5.ed. São Paulo: Ática, 2005.

SEF. Parâmetros Curriculares Nacionais: terceiro e quarto ciclos do ensino fundamental: Língua Portuguesa. Brasília: MEC/SEF, 1998. 